\section{Brasil e China à luz da juventude universitária: um projeto pioneiro}

DWYER, Tom et alii (Orgs.). Jovens universitários em um mundo em transformação: uma pesquisa sino-brasileira. Brasília; Pequim: Ipea; SSAP, 2016.

\section{Cristina Patriota de Moura*}

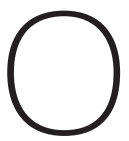

livro Jovens universitários em um mundo em transformação é fruto de mais de uma década de diálogos entre pesquisadores brasileiros e chineses. Vem publicado, simultaneamente, no Brasil (em português) e na China (em mandarim), com traduções diretas dos idiomas originais em que os diferentes capítulos foram escritos.

Segundo nos conta o principal organizador do lado brasileiro, Tom Dwyer, em sua "Introdução", tal colaboração se iniciou com a ida da primeira delegação da Sociedade Brasileira de Sociologia (SBS) a Pequim, em 2004. Nessa ocasião foi firmado acordo entre a SBS e o Centro de Pesquisa em Infância e Juventude da China $(C Y C R C)^{1}$, que gerou quatro visitas de delegações chinesas ao Brasil e mais três idas de delegações brasileiras à China. Tais encontros geraram um projeto de pesquisa comparativa, quando se realizou um survey com estudantes universitários em duas cidades em cada país, capitais financeiras (São Paulo e Xangai) e capitais políticas (Brasília e Pequim). No caso brasileiro, foi firmado ainda um convênio entre a SBS e o Instituto de Pesquisas Econômicas Aplicadas (Ipea), que garantiu apoio técnico e financiamento à execução da pesquisa.

Os organizadores da publicação são Tom Dwyer (Unicamp), Eduardo Luiz Zen (Ipea), Wivian Weller (UnB), Jiu Shuguang (CYCRC) e Guo Kaiyuan (CYCRC). A obra traz doze capítulos, a maioria dos quais discute diretamente os dados obtidos a partir da resposta aos questionários (2.429 validados no Brasil e 1.729 na China), todos executados ao longo do ano de 2012. Os questionários foram direcionados a estudantes entre 18 e 24 anos matriculados em cursos de graduação em três tipos de instituição de ensino universitário em cada país correspondentes a diferentes "camadas" (A, B e C), sendo o primeiro nível de universidades nacionais de excelência, o segundo de universidades nacionais "regulares" e o terceiro de universidades locais, conforme especificado pela equipe chinesa no apêndice B (p. 307).
Recebido: 01.04.17

Aprovado: 05.07.17

\author{
* Professora \\ associada do \\ Departamento de \\ Antropologia da UnB. \\ Autora de livros e \\ artigos na área de \\ antropologia urbana, \\ incluindo processos \\ de urbanização \\ chinesa. Atualmente, \\ pesquisa trajetórias \\ transnacionais \\ de estudantes \\ universitários \\ chineses. \\ <patriotademoura@ \\ gmail.com>. \\ 1. Em inglês, China \\ Youth and Children \\ Research Center.
}


No Brasil, a coordenação da pesquisa contou com seis professores universitários e um analista do Ipea, mestre em sociologia. A equipe de pesquisa, do Ipea, foi formada por cinco pesquisadores. Do lado chinês, a coordenação da pesquisa foi composta por três pesquisadores, todos diretores do CYCRC, e dez membros da equipe de pesquisa, vinculados também ao CYCRC. O responsável pelo convênio CYCRC/ Ipea do lado chinês foi Jiu Shuguang, diretor-geral do CYCRC. Do lado brasileiro, o professor Tom Dwyer, então presidente da Sociedade Brasileira de Sociologia, foi o coordenador do convênio SBS/Ipea.

Há artigos escritos individualmente e outros de autoria coletiva. Além dos membros das equipes brasileira e chinesa, os sociólogos Carlos Benedito Martins e Clarissa Baeta Neves foram convidados a colaborar com um artigo sobre as transformações do ensino superior no Brasil e, portanto, assinam o capítulo III, intitulado "Ensino superior no Brasil: uma visão abrangente", que traz importante contextualização da recente expansão do ensino superior no Brasil e as políticas de internacionalização implementadas até o final do primeiro mandato de Dilma Roussef.

Do lado brasileiro, destaca-se a formação em sociologia e/ou educação dos pesquisadores, à exceção da demógrafa Ana Maria Nogales Vasconcelos, que assina o capítulo IV e o apêndice A, que apresenta a metodologia de amostragem e a análise quantitativa utilizada pela equipe brasileira. Já o apêndice B, sobre a metodologia de amostragem utilizada na China, é assinada pela equipe chinesa, sem indicação de nomes específicos.

A obra começa com uma introdução brasileira de Tom Dwyer e outra chinesa, assinada por Guo Kayuan, diretor do Instituto de Pesquisa de Direito da Juventude e Infância da China do CYCRC. Em seguida, somos brindados com quatro capítulos que apresentam os sistemas de educação superior nos dois países, em sua relação com dados demográficos sobre cada um dos países. Ao passo que os capítulos III e IV contextualizam o caso brasileiro, os dois primeiros capítulos nos trazem importantes informações sobre o contexto chinês: Gao Yingshuang assina o capítulo intitulado "Situação atual e tendência de desenvolvimento do sistema de educação superior na China", ao passo que o segundo capítulo, "Análise da dinâmica demográfica da China" é assinado pela dupla Yang Jianglan e Wang Jie. Vemos, nesses capítulos, uma narrativa acerca das acentuadas transformações ocorridas nas últimas décadas, quando houve a passagem de um sistema de ensino superior gratuito para um sistema pago, apesar de subsidiado pelo Estado, em diferentes escalas administrativas. Somos também apresentados aos fortes investimentos no sentido de promover não somente a expansão do ensino superior, mas também a qualificação de instituições universitárias de nível global, em políticas como os projetos 211 e 985, "que 
objetivam colocar a educação superior do país no patamar de excelência mundial e fomentar um desenvolvimento diferenciado e avançado de ensino" (p. 54).

Percebe-se que todos os envolvidos têm grande respeito pelas análises dos colegas do outro lado do globo e o tom de cooperação, respeito mútuo e desejo de compreensão recíproca é evidente ao longo do livro, que não deixa de ser um empreendimento diplomático, além de acadêmico.

\begin{abstract}
O projeto que culminou neste livro teve por base a ideia de que as pesquisas em ciências sociais podem auxiliar na construção de uma ponte entre a total falta de conhecimento e um conhecimento mais preciso, e na necessidade de nosso pais conhecer melhor a China e seu povo, e vice-versa (p. 15).
\end{abstract}

Não obstante a intenção de construir diálogos convergentes, já na primeira parte do livro é notável a diferença de estilo e tom entre os escritos realizados por brasileiros e por chineses. Os textos brasileiros são mais descritivos e analíticos, enquanto os chineses têm uma construção normativa bastante explícita. Por um lado, pode-se atribuir essas diferenças à formação profissional dos próprios pesquisadores, que, no caso chinês, consiste principalmente em direito e economia. Sabemos também que o Partido Comunista Chinês direciona os discursos dos centros de pesquisa sob sua supervisão e que as próprias universidade alinham seus discursos oficiais com aquele do governo central. Assim, encontramos frases como "a harmonia e a estabilidade social têm sido promovidas" (p. 49), que poderiam causar algum estranhamento a leitores acadêmicos brasileiros.

Do quinto capítulo em diante o livro inicia a empreitada de comparar os dados obtidos a partir das respostas aos questionários. Aprendemos então que os jovens de ambos os países valorizam a família: "[...] o que impressiona é que apesar de todas as transformações sofridas nas duas sociedades, a família continua sendo uma referência fundamental" (p. 147). A política do filho único implementada na China e as mudanças na estrutura familiar brasileira ao longo das últimas décadas certamente reconfiguraram as relações familiares, mas a família é apontada como a instituição em que os jovens de ambos os países mais confiam. Nesse ponto, diversos textos apontam "diferenças culturais" onde uma das referências fundamentais é o antropólogo/sociólogo Fei Xiaotong (1992), que propôs uma tipologia entre modos de associação entre a China e o "Ocidente": enquanto a primeira teria um modo diferencial de associação, onde cada tipo de relação obedece a uma ética própria, as sociedades modernas ocidentais se organizariam segundo o "modo organizacional de associação", com regras mais impessoais. Dwyer cita Fei Xiaotong e classifica a família brasileira como ocidental, em diálogo com o trabalho pioneiro de Teixeira Leite (1999): 
Fei Xiaotong (1992) ensina que o papel da família chinesa tradicional é mais de ordem funcional, segundo ele; a família brasileira - cuja base é ocidental - teria um papel mais de apoio emocional, sem descartar seu papel funcional (p. 147).

Além do nível de confiança em instituições, a pesquisa procurou levantar dados sobre valores pessoais e "de juventude", trajetórias e projetos escolares e profissionais, medos e inseguranças, além de conhecimento recíproco sobre a realidade dos países da pesquisa.

Uma diferença importante está na conciliação da vida universitária com atividades laborais. Trabalhar em tempo integral e cursar uma universidade é uma prática quase inexistente entre chineses da faixa etária pesquisada (18 a 24 anos). Já no Brasil é muito comum estudar e trabalhar por mais de 20 horas semanais. As horas dedicadas ao estudo dentro e fora de sala de aula também são bem mais numerosas entre os chineses. Os capítulos VI e VII analisam os dados sobre contextos familiares e trabalho. Wivian Weller, Chen Weidong e Lucélia Bassalo assinam o capítulo VI, "Origem familiar, percursos acadêmicos e projetos de estudantes universitários brasileiros e chineses", ao passo que Luiz Eduardo Zen escreve o capítulo VII, "Os jovens universitários e o trabalho: uma visão comparada entre Brasil e China". Os dois capítulos analisam dados sobre a origem e a ocupação dos pais, bem como o cotidiano e os projetos profissionais futuros.

De treze valores elencados, a maioria dos jovens dos dois países escolheu os mesmos cinco valores: ética e honestidade, justiça, solidariedade, valorização da família e igualdade. Não obstante, enquanto no Brasil ficaram em primeiro lugar ética/honestidade, solidariedade e família, entre os chineses os valores pessoais aos quais se atribui mais importância são igualdade, liberdade e, em terceiro lugar, justiça no caso dos homens e família no caso das mulheres. Encontramos análises desses dados nos capítulos VIII e IX, escritos, respectivamente, por Guo Kayuan, Yang Shoujian, Chen Chen e Wang Peng (capítulo VIII) e Marília Sposito, Marilena Nakano e Chen Chen (capítulo IX). Esses capítulos também analisam dados sobre formas de estabelecimento de amizade. Enquanto jovens de ambos os países dizem ter, em média, mais de dez amigos, há importante diferenças nas instâncias de estabelecimento de amizades. Enquanto na China a grande maioria das amizades foi estabelecida com colegas de escola e universidade, no Brasil, relações familiares e de vizinhança, além do pertencimento a religiões, são fatores de grande relevância. Enquanto $80,9 \%$ das mulheres e $68,7 \%$ dos homens brasileiros dizem ter vínculos religiosos, esse número cai para $15,5 \%$ das mulheres e $13 \%$ dos homens chineses, entre os quais a maioria adere ao budismo. Acredito que tais dados poderiam ser contrapostos à tipologia de Fei Xiaotong, construída ainda na primeira metade do 
século XX. Os dados parecem apontar para uma maior relevância de pertencimento a organizações formais na China do que no Brasil. O formato do livro, no entanto, que reúne pesquisadores de reconhecida qualidade acadêmica em suas áreas, parece não incentivar análises mais aprofundadas, mesmo porque os investimentos prévios dos pesquisadores são em pesquisa sobre educação e ensino superior, mas não sobre as diferenças culturais entre Brasil e China.

Diferenças de valores pessoais parecem não ser tão acentuadas quanto aquelas que aparecem em relação a outra categoria do questionário: valores da juventude. Os Chineses, por exemplo, se preocupam muito com o "declínio moral", coisa que não acontece de forma significativa entre os brasileiros.

Os três últimos capítulos, todos assinados por membros da equipe chinesa, retomam o tom programático já percebido em capítulos anteriores. O capítulo X, "A orientação de valores dos universitários chineses contemporâneos e suas mudanças", é assinado pesquisador do CYCRC Wang Peng, mestre em educação e doutor em política pela Escola do Comitê Central do Partido Comunista. Com foco na "orientação de valores", definida como "princípio, crença e juízo de valor que motivam e direcionam a ação e a decisão de um indivíduo" (p. 263), é interessante notar a periodização apresentada, que começa em 1978, um ano após a retomada do exame nacional de admissão universitária - o gaokao -, que havia sido suspenso durante os primeiros anos da República Popular da China até a morte de Mao Tse Tung e o fim da Revolução Cultural. Os quatro períodos elencados falam em jovens "confusos" (1978-1980), em seguida (1980-1990) sujeitos a "influências da política democrática ocidental" (p. 265) que levaram à "falta de autocontrole dos universitários" (p. 266); para então procurar, na década seguinte, se dedicarem à eliminação dos conflitos entre si próprios e a sociedade" (p. 267). Atualmente, diz o autor, a maioria dos universitários é "filho único e egocêntrico", mas é necessário trabaIhar em prol da eficácia da educação moral" para ajudar os jovens a "transcender a orientação de valores de base emocional para a racional” (p. 272).

O capítulo XI, "Quadro da participação dos universitários chineses na política e seu aperfeiçoamento", escrito por Jiu Shuguang e Guo Kaiyuan, repete o tom do capítulo anterior, na preocupação de definir princípios de participação política, que deve ser "legal, organizada, ampla e igualitária" (p. 281). Nesse capítulo vemos que a participação política é definida principalmente por meio da filiação de jovens a grupos sob a égide do Partido Comunista Chinês. Vemos também a preocupação com o uso da internet como meio de expressão política por jovens, que deve ser "consciente, civilizada e racional", "evitando a tendência 'temperamental' da participação política no mundo virtual" (p. 285). 
O último capítulo, de Chen Weidong, intitula-se "Valores, origens sociais, estilos de vida e horizontes dos universitários chineses". O texto retoma os principais temas tratados no questionário e apresenta uma síntese dos dados levantados. Além das diferenças já mencionadas em capítulos anteriores entre cotidiano e experiências profissionais dos jovens universitários, Chen reitera o caráter "relativamente monótono" da vida de lazer dos universitários chineses, que saem pouco de casa e têm como principal passatempo passeios a shoppings e uso de internet: "nos finais de semana e férias, acessar a internet é a atividade mais recorrente dos universitários" (p. 296). Em capítulos anteriores soubemos que os jovens brasileiros frequentam bares e boates regularmente, o que é uma prática irrisória e tratada com repreensões na China. Também frequentam igrejas e casas de amigos bem mais que os chineses. Já um dos fatores que mais preocupa os brasileiros em seu cotidiano é a violência urbana, incompreendida pelos chineses.

Finalmente, ao longo do livro constatamos que jovens brasileiros e chineses sabem pouquíssimo a respeito do país parceiro desta pesquisa. Esse desconhecimento também se dá entre a população de forma mais geral e, especificamente, no meio acadêmico. Assim sendo, esse trabalho pioneiro tem grandes méritos e vale a pena debruçarmo-nos sobre os dados e as análises trazidas ao longo do livro, além de esperar que projetos colaborativos e comparativos proliferem entre pesquisadores do Brasil e da China.

\section{Referências}

FEI, Xiaotong. From the soil: the foudations of chinese society. Berkeley; Los Angeles: University of California Press, 1992.

TEIXEIRA LEITE, José Roberto. A China no Brasil: influências, marcas, ecos e sobrevivências chinesas na sociedade e na arte brasileiras. Campinas: Editora Unicamp, 1999. 